А. А. Гришкевич, С. А. Гриневич, Г. В. Алифировец

Белорусский государственный технологический университет

\title{
ОСОБЕННОСТИ КОНСТРУКЦИИ ПИЛЫ ДИСКОВОЙ СБОРНОЙ ДЛЯ РЕЗАНИЯ ДРЕВЕСИНЫ
}

Резание древесины и древесных материалов с использованием лезвийного инструмента является широко используемым видом обработки при изготовлении мебели, столярных изделий, получении щепы и других видов продукции. Механическая обработка древесины и древесных материалов дисковыми пилами занимает в этих видах производств одно из ведущих мест.

Технический прогресс в деревообрабатывающей промышленности, автоматизация и интенсификация технологических процессов, а также повышение качества и точности обработки древесных материалов предъявляют к режущему инструменту все более высокие требования.

Одно из основных требований - высокая производительность. Существует множество конструкций пил дисковых, увеличивающих производительность самого инструмента, однако повышение производительности за счет уменьшения времени на замену инструмента не имеет такого же многообразия конструкций.

Современный дереворежущий инструмент должен обеспечивать точность и качество обработки, обладать высокой износостойкостью, надежностью и долговечностью, быть удобным в подготовке к эксплуатации, обладать минимальным шумообразованием.

В данной работе рассматривается пила дисковая, конструкция которой предполагает уменьшение время простоя оборудования при замене инструмента. При ее проектировании проведены необходимые расчеты на ее работоспособность, разработаны чертежи.

Ключевые слова: резание, пила дисковая, производительность, силы резания, угловые параметры.

Для цитирования: Гришкевич А. А., Гриневич С. А., Алифировец Г. В. Особенности конструкции пилы дисковой сборной для резания древесины // Труды БГТУ. Сер. 1, Лесное хоз-во, природопользование и перераб. возобновляемых ресурсов 2021. № 2 (246). С. 320-326.

\section{A. A. Grishkevich, S. A. Grinevich, G. V. Alifirovets}

Belarusian State Technological University

\section{DESIGN FEATURES OF THE CIRCULAR SAW FOR WOOD CUTTING}

Cutting wood and wood materials using a blade tool is a widely used type of processing in the manufacture of furniture, joinery, wood chips and other products. Mechanical processing of wood and wood materials with circular saws occupies one of the leading places in these types of production.

Technological progress in the woodworking industry, automation and automation of technological processes, as well as improving the quality and accuracy of processing wood materials, place ever higher demands on the cutting tool.

One of the main requirements for the tool is high performance. There are many designs of circular saws that increase the productivity of the tool itself, but increasing productivity by reducing the time to replace the tool does not have the same variety of designs.

Modern wood-cutting tools must ensure the accuracy and quality of the work, have high wear resistance, reliability and durability, be convenient in preparation for operation, and have minimal noise generation.

In this paper, we consider a circular saw, the design of which involves reducing the downtime of the equipment when replacing the tool. When designing it, the necessary calculations were made for its operability, and drawings were developed.

Key words: milling, profiling, cutting forces, angular parameters.

For citation: Grishkevich A. A., Grinevich S. A., Alifirovets G. A. Design features of the circular saw for wood cutting. Proceedings of BSTU, issue 1, Forestry. Nature Management. Processing of Renewable Resources, 2021, no. 2 (246), pp. 320-326 (In Russian).

Введение. Пиление древесины круглыми (дисковыми) пилами - самый распространенный процесс механической технологии, отличающийся большим разнообразием конструкций и технологических схем станков [1]. Простота устройства станков, относительно низкая стоимость и высокая производительность способствуют их использованию на всех делительных 
операциях первичной и вторичной обработки древесины.

Основная часть. Целью работы является разработка конструкции пилы дисковой со съемными сегментами, дающими возможность сохранить длительный срок службы корпуса пилы и улучшить условия ее замены на шпинделе станка. Выполнив патентный обзор: патент BY 7982 U «Дисковая пила» [2], патент RU 2690879 C1 «Круглая пила по дереву c эффектом самозатачивания» [3], патент SU 1544558 A1 «Дисковая пила» [4], определим задачи проекта.

Задачами работы являются:

- рассчитать силы и мощность резания, режимы эксплуатации, конструктивные элементы и проанализировать работу пилы дисковой сборной;

- провести теоретические исследования с целью определения условий эксплуатации новой конструкции пилы.

На рис. 1 представлена схема пиления дисковыми пилами.

Рассмотрев конструкции дисковых пил, можно провести параллели с металлообработкой, где применяется пила Геллера [5]. Она используется для резки черного и цветного металла при помощи дисковых пил. Сегментная пила является режущим устройством и важной частью фрезерно-отрезного станка, ее главная задача обработка различных заготовок из металла. Этот инструмент представляет собой диск с закрепленными по краю зубьями, которые называются сегментами. Процесс резки происходит под прямым углом диска к самой заготовке [6].

Способность обрабатывать металлические формы любых размеров возможна благодаря определенным сегментам с разными характеристиками [7].
Для проектирования пилы будем использовать многопильный станок с частотой вращения 4400 мин $^{-1}$. Высота пропила составляет от 15 до 200 мм, а также данный станок имеет жесткую конструкцию, рассчитанную на тяжелые условия работы [8].

Принципиальный вид проектируемой пилы дисковой со съемными сегментами представлен на рис. 2.

Для определения режимов эксплуатации пилы дисковой сборной необходимо произвести расчет скорости резания. Для круглопильного станка примем частоту вращения пилы $n=4400$ мин $^{-1}$, а максимальный диаметр пил $D=320$ мм.

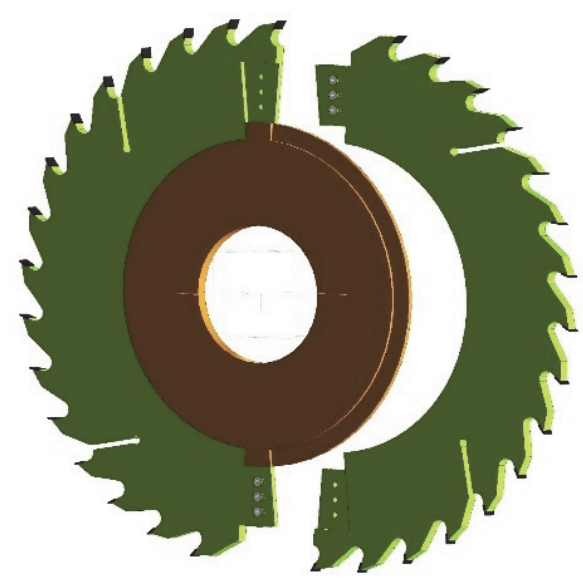

Рис. 2. Принципиальный вид проектируемой пилы дисковой сборной

Скорость главного движения $V, \mathrm{~m} / \mathrm{c}$, определим по формуле [9].

$$
V=\frac{3,14 \cdot 320 \cdot 4400}{60 \cdot 1000}=73,7 \mathrm{~m} / \mathrm{c} .
$$

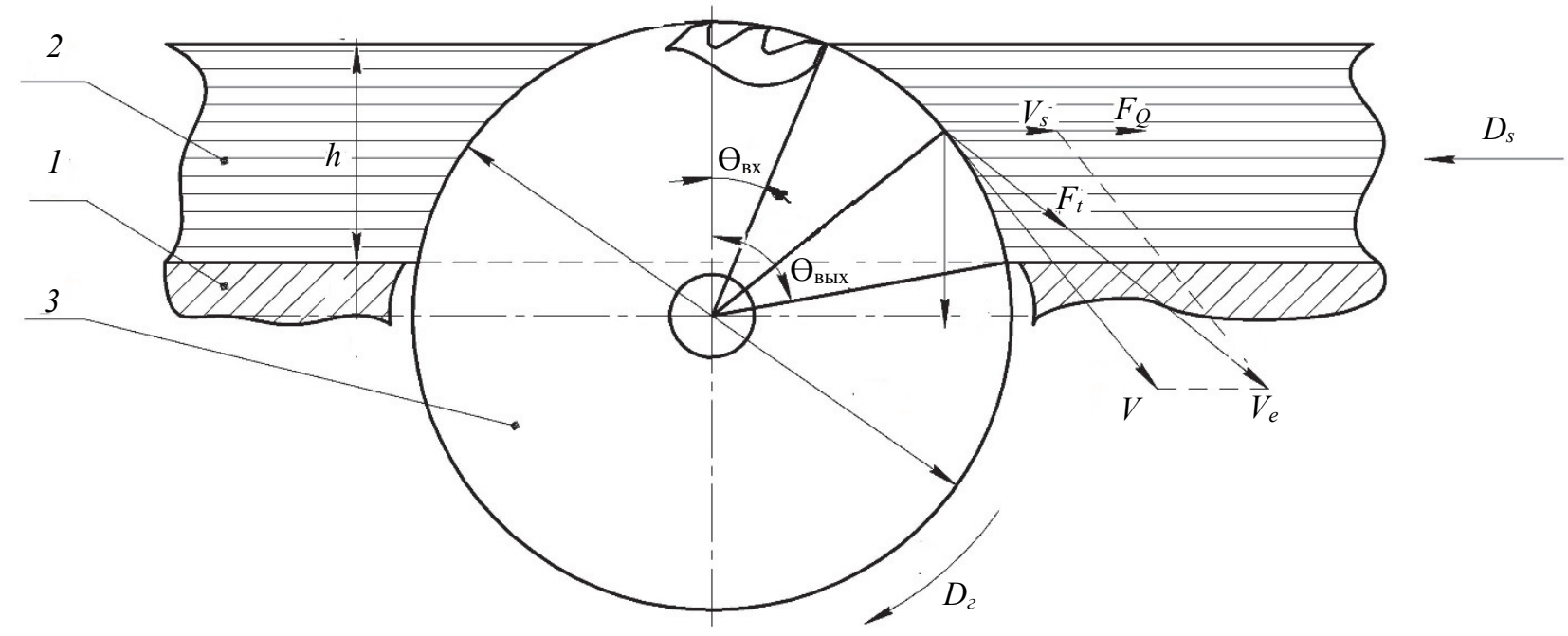

Рис. 1. Схема пиления дисковыми пилами:

1 - стол; 2 - распиливаемый материал; 3 - пила 
Диаметр пилы и количество зубьев выбраны по конструкторским соображениям: $D=320$ мм, $z=32$. Расчет длины дуги контакта $l_{\kappa}$, мм, и шага $t$, мм, выполнено графически с помощью программы «Компас-3D v18.1».

Определение массы и расстояния от оси вращения до центра масс съемного сегмента выполнено графически с помощью программы «Компас-3D v18.1» (рис. 3).

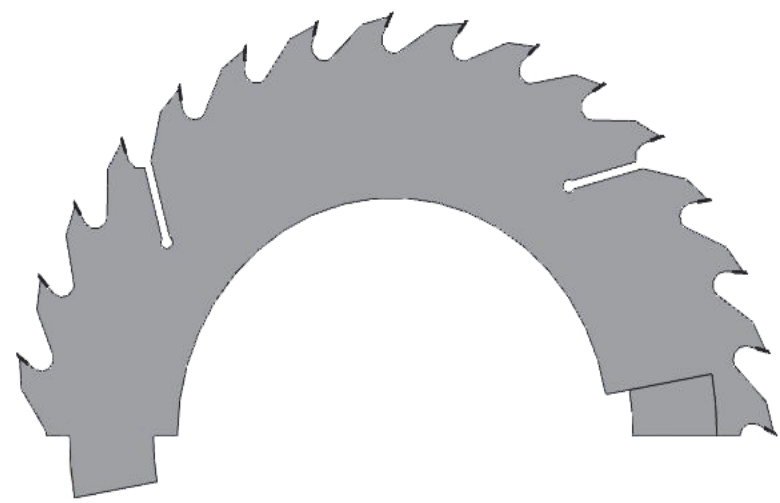

Рис. 3. Графическое определение параметров съемного сегмента

Составим схему действующих сил на сегмент в процессе пиления (рис. 4).

Определим проекции сил на ось $y$. Проекцию сил инерции $F_{\text {и }}{ }^{\prime}, \mathrm{H}$, сегмента на ось $y$ рассчитаем как произведение силы инерции $F_{\text {и }}=10179 \mathrm{H}$ на косинус угла между вектором силы инерции и осью $y, 0^{\circ}$, определенный графически с помощью программы «Компас-3D v18.1».

$$
F_{\text {и }}{ }^{\prime}=10179 \cdot \cos (0)=10179 \mathrm{H} .
$$

Выполним расчет радиальной $F_{r 1}, \mathrm{H}$, и касательной $F_{t 1}, \mathrm{H}$, силы резания для первого зуба. Проекцию радиальной силы от первого зуба $F_{r 1}$ рассчитаем как произведение радиальной силы $F_{r}=9,81$ Н на синус угла между силой и плоскостью, перпендикулярной плоскости $y, 11,22^{\circ}$, рассчитанный графически с помощью программы «Компас-3D v18.1».

$$
F_{r 1}=9,81 \cdot \sin (11,22)=1,9 \mathrm{H} \text {. }
$$

Проекцию касательной силы от первого зуба $F_{t 1}$ вычислим как произведение касательной силы $F_{t}=37,9 \mathrm{H}$ на косинус угла между силой и плоскостью $y, 11,22^{\circ}$, найденный графически с помощью программы «Компас-3D v18.1».

$$
F_{t 1}=37,9 \cdot \cos (11,22)=37,17 \mathrm{H} \text {. }
$$

Расчет касательных и радиальных сил произведем аналогичным образом [10]. Значения сил составят: $F_{t 2}=35,02 \mathrm{H}, F_{r 2}=3,75 \mathrm{H}$, $F_{t 3}=31,52 \mathrm{H}, F_{r 3}=5,44 \mathrm{H}, F_{t 4}=26,81 \mathrm{H}$, $F_{r 4}=6,93 \mathrm{H}, F_{t 5}=21,07 \mathrm{H}, F_{r 5}=8,15 \mathrm{H}$, $F_{t 6}=14,52 \mathrm{H}, F_{r 6}=9,06 \mathrm{H}$.

Для расчета крепления предварительно выберем винт А2.М3-6gx3,5.109 (ГОСТ 17475) [11] исходя из конструкторских соображений. Допускаемое напряжение смятия и среза для данного винта составляет $\left[\tau_{\mathrm{cp}}\right]=270$ МПа и $\left[\sigma_{\mathrm{cm}}\right]=360$ МПа соответственно [12].

Схема нагружения винта представлена на рис. 5.

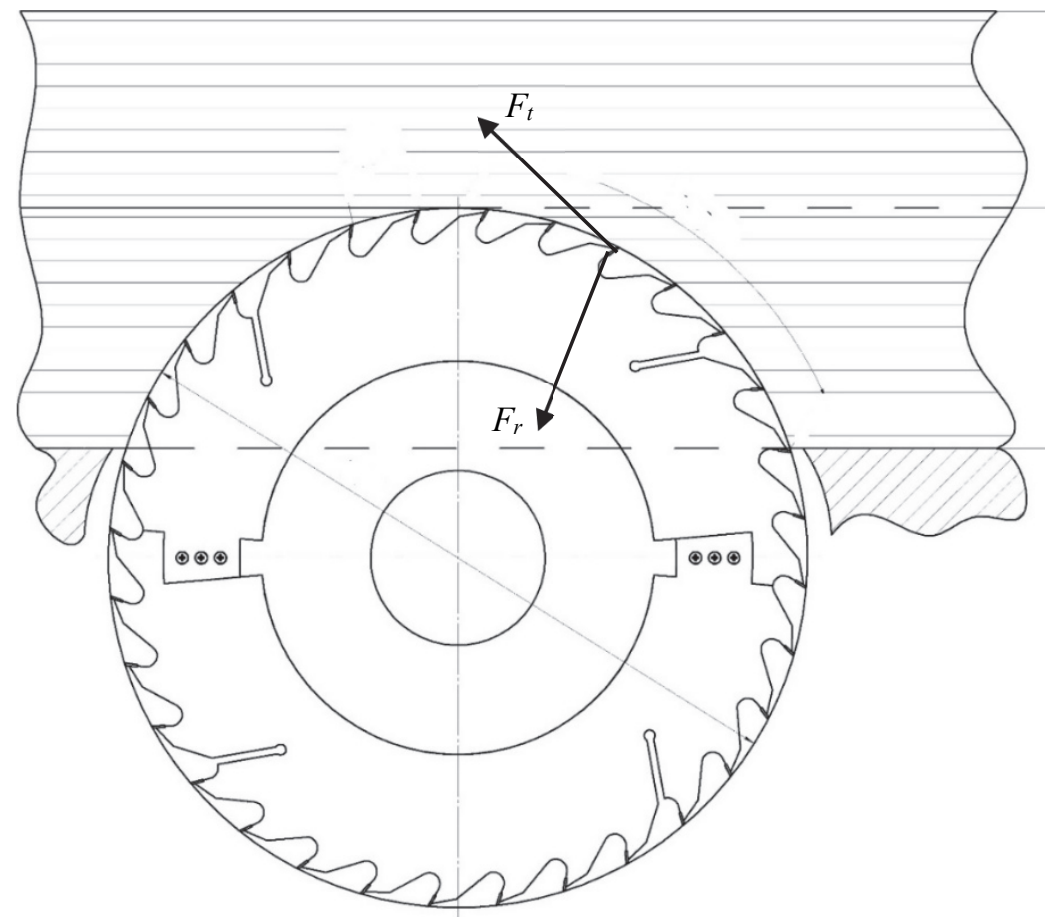

Рис. 4. Схема сил, действующих на сегмент 


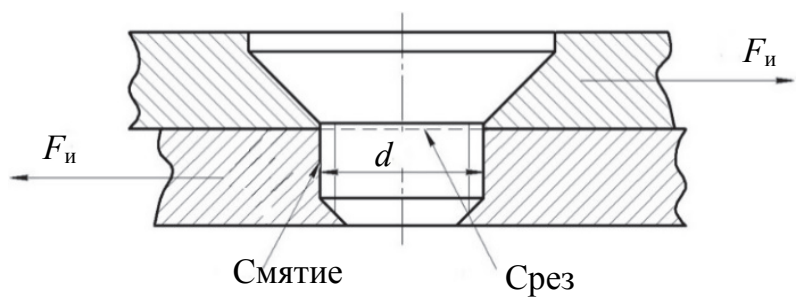

Рис. 5. Схема нагружения элементов крепления сегмента

Итогом данного расчета является то, что для выполнения условия прочности каждый съемный сегмент потребуется крепить 6 винтами A2.M3-6gx3,5.109 (ГОСТ 17475).

Целью теоретических исследований является изучение работы новой конструкции пилы дисковой сборной при разных частотах вращения, а также при разном количестве крепежных винтов и их диаметра.

Задачей исследования является определение:

- влияния частоты вращения пилы $n$, мин $^{-1}$, на напряжения среза $\tau_{\mathrm{cp}}$, МПа, и смятия $\sigma_{\mathrm{cm}}, \mathrm{MПа}$, винтов, а также максимально допустимой частоты ее вращения по каждому из напряжений;

- зависимости диаметра резьбы винта $d$, мм, их количества от напряжения среза $\tau_{\text {ср }}$, МПа, и смятия $\sigma_{\mathrm{cm}}$, МПа, а также минимального их количества и диаметра для выполнения условия прочности.

Данные для этого графика представлены в табл. 1.

На рис. 6 изображен график зависимости частоты вращения $n$, мин $^{-1}$, от напряжения среза $\tau_{\text {ср }}$, МПа, и смятия $\sigma_{\text {см}}$, МПа [9].

Таблица 1

Зависимость частоты вращения от напряжения среза $\tau_{\text {ср, }}$ МПа, и смятия $\sigma_{c м}$, МПа

\begin{tabular}{|c|c|c|c|c|c|c|}
\hline $\begin{array}{c}\text { Частота } \\
\text { вращения } n, \\
\text { мин }^{-1}\end{array}$ & $\begin{array}{c}\text { Угловая } \\
\text { скорость } \omega, \\
\text { рад/с }\end{array}$ & $\begin{array}{c}\text { Сила } \\
\text { инерции } F_{\text {и, }} \text {, } \\
\text { H }\end{array}$ & $\begin{array}{c}\text { Напряжение } \\
\text { среза } \tau_{\mathrm{cp}}, \\
\text { МПа }\end{array}$ & $\begin{array}{c}\text { Напряжение } \\
\text { смятия } \sigma_{\mathrm{cm}}, \\
\text { МПа }\end{array}$ & $\begin{array}{c}\text { Допускаемое } \\
\text { напряжение } \\
\text { среза для } \\
6 \text { винтов } \\
{\left[\tau_{\mathrm{cp}}\right]^{\prime}, \text { МПа }}\end{array}$ & $\begin{array}{c}\text { Допускаемое } \\
\text { напряжение } \\
\text { смятия для } \\
6 \text { винтов } \\
{\left[\sigma_{\mathrm{cm}}\right]^{\prime}, \text { МПа }}\end{array}$ \\
\hline 2000 & 209,4 & 2015,5 & 401,1 & 297,9 & \multirow{9}{*}{1620} & \multirow{9}{*}{2160} \\
\hline 2500 & 261,8 & 3289,9 & 626,6 & 465,4 & & \\
\hline 3000 & 314,2 & 4737,4 & 902,4 & 670,2 & & \\
\hline 3500 & 366,5 & 6448,1 & 1228,2 & 912,2 & & \\
\hline 4000 & 418,9 & 8422,1 & 1604,2 & 1191,5 & & \\
\hline 4500 & 471,2 & 10659,2 & 2030,3 & 1508,0 & & \\
\hline 5000 & 523,6 & 13159,5 & 2506,6 & 1861,7 & & \\
\hline 5500 & 576,0 & 15923,0 & 3032,9 & 2252,6 & & \\
\hline 6000 & 628,3 & 18949,6 & 3609,5 & 2680,8 & & \\
\hline
\end{tabular}

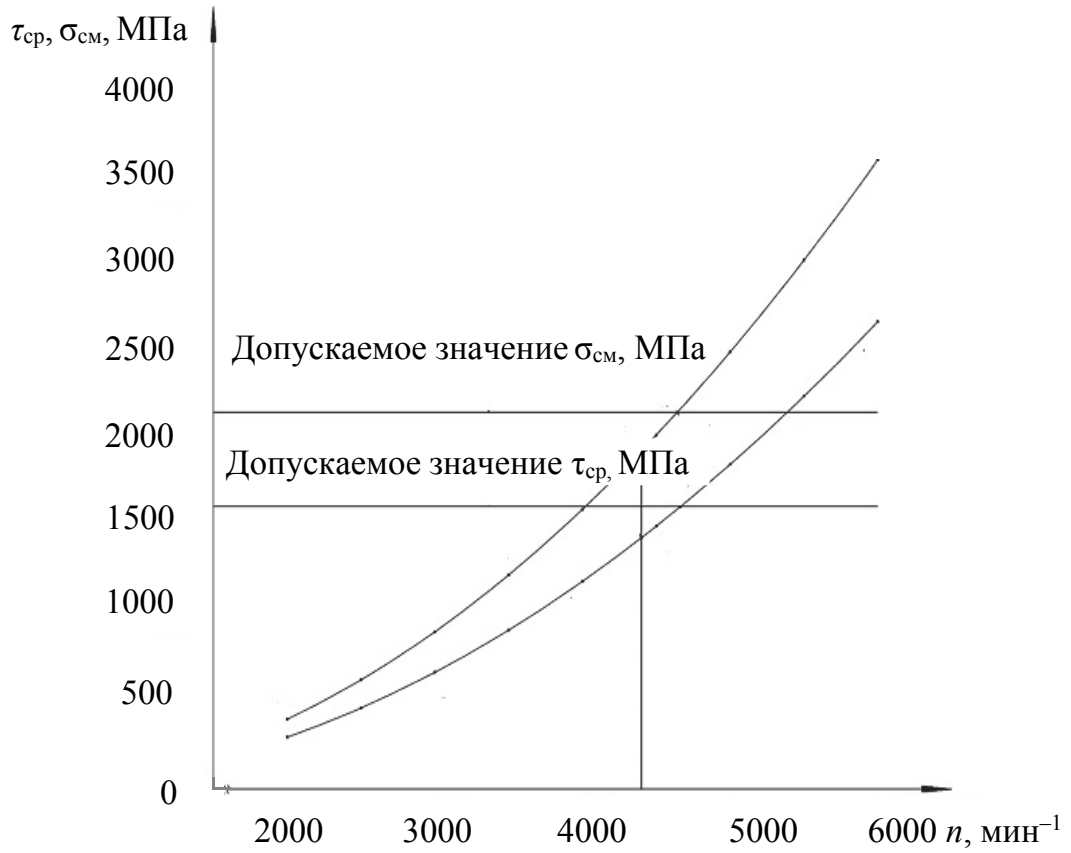

Рис. 6. График зависимости частоты вращения $n$, мин ${ }^{-1}$ от напряжения среза $\tau_{\mathrm{cp}}$, MIІа, и смятия $\sigma_{\mathrm{cm}}$, МПа 
Графики зависимости диаметра резьбы винта $d, \quad$ и смятия $\sigma_{\text {см }}$ МПа, представлены на рис. 7 и 8 , мм, и их количества от напряжения среза $\tau_{\text {cр, }}$ МПа, д данные для этих графиков приведены в табл. 2.

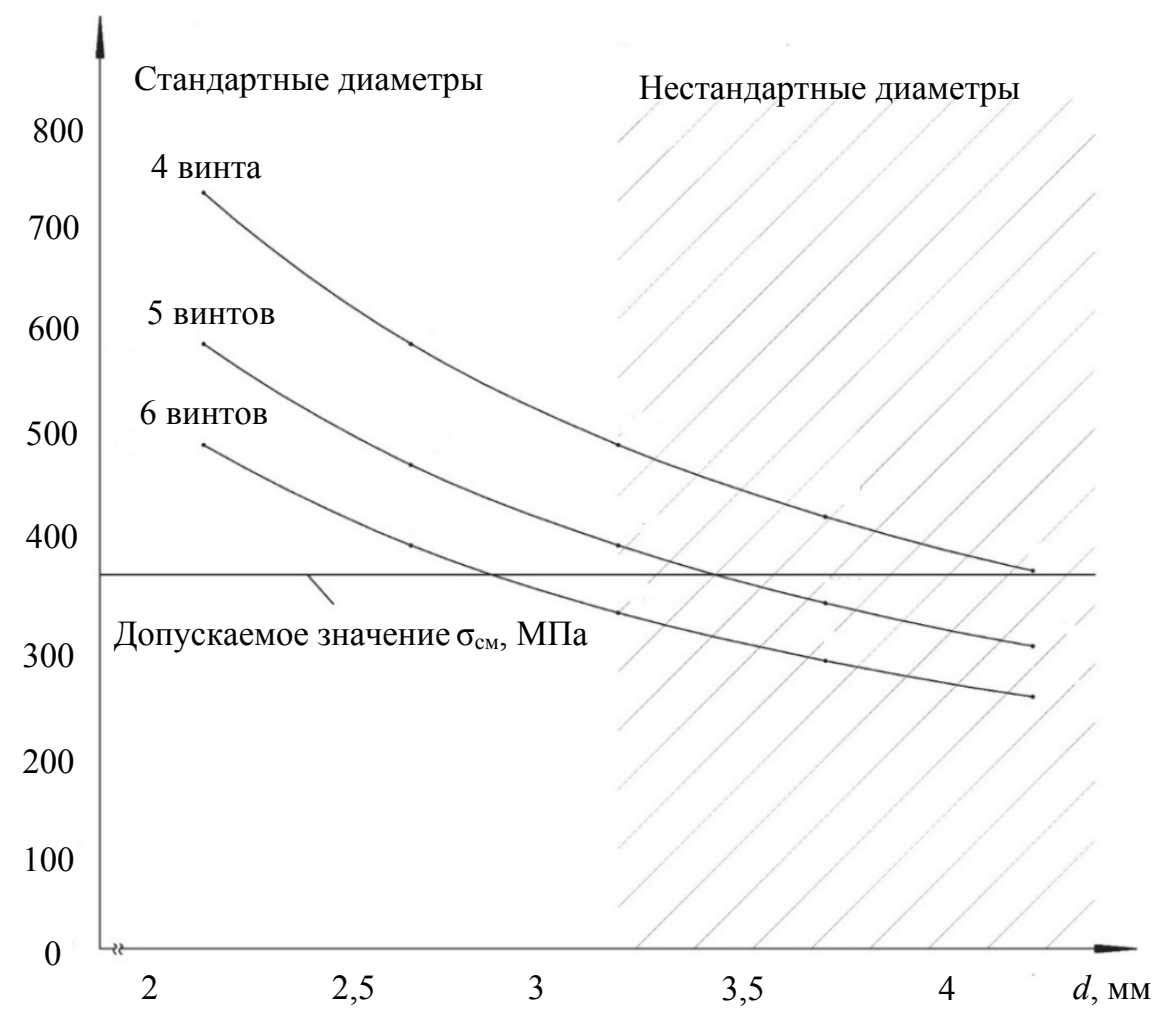

Рис. 7. График зависимости диаметра резьбы винта $d$, мм, и их количества от напряжения смятия $\sigma_{\mathrm{cm}}$, Мпа

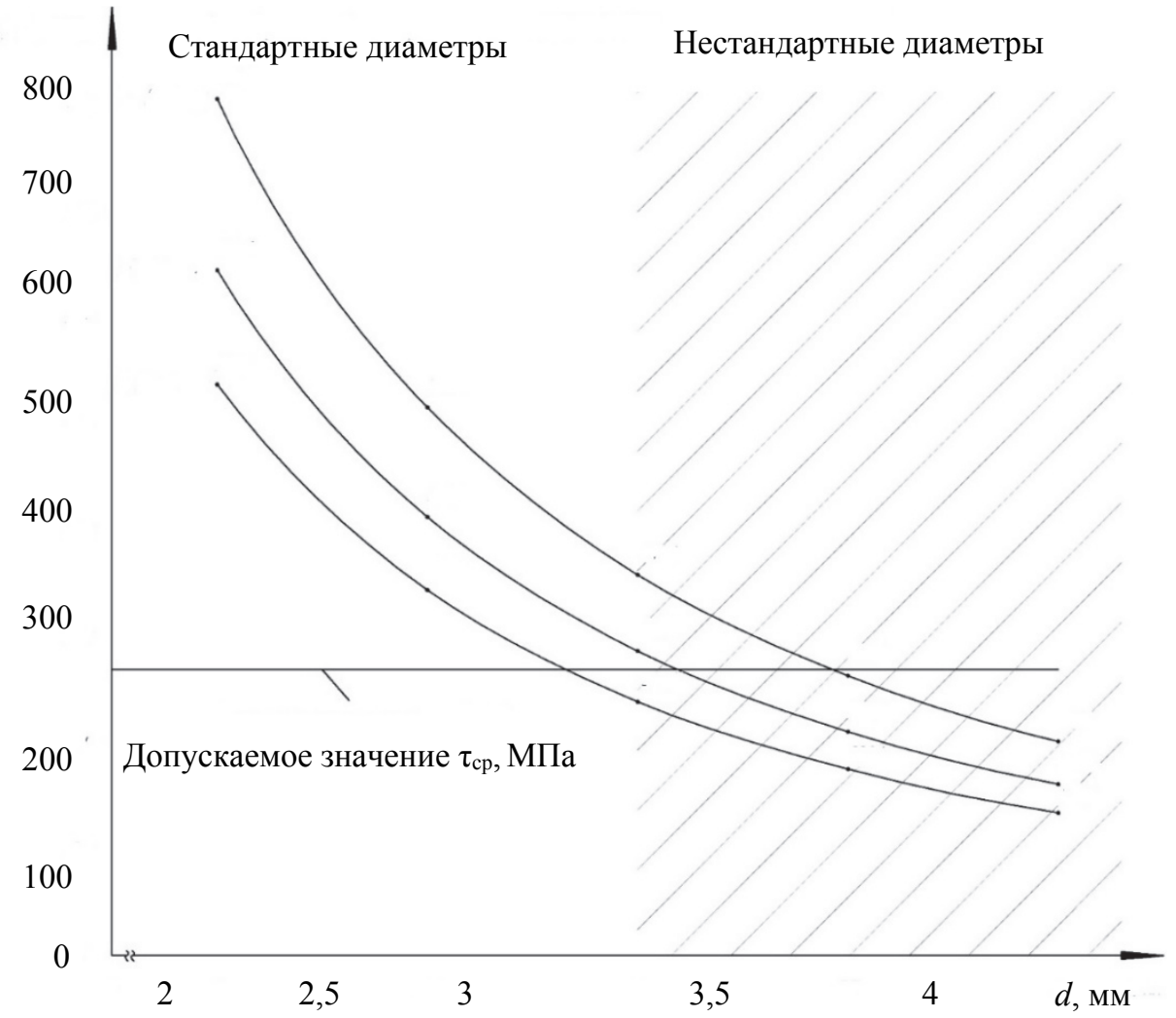

Рис. 8. График зависимости диаметра резьбы винта $d$, мм, и их количества от напряжения среза $\tau_{\mathrm{cp}}$, МПа 
Таблица 2

Зависимость диаметра резьбы винта $d$, мм, и их количества от напряжения среза $\tau_{c p}$, МПа, и смятия бсм, МПа

\begin{tabular}{|c|c|c|}
\hline Диаметр резьбы винта $d$, мм & $\begin{array}{c}\text { Напряжение среза на } 1 \text { винт } \tau_{\mathrm{cp}}{ }^{\prime}, \\
\text { МПа }\end{array}$ & $\begin{array}{c}\text { Напряжение смятия на } 1 \text { винт } \\
\sigma_{\mathrm{cm}}{ }^{\prime}, \text { МПа }\end{array}$ \\
\hline 1 & 2 & 3 \\
\hline \multicolumn{3}{|c|}{4 винта } \\
\hline 2 & 810,0 & 727 \\
\hline 2,5 & 518,4 & 581,7 \\
\hline 3 & 360,0 & 484,7 \\
\hline 3,5 & 264,5 & 415,5 \\
\hline 4 & 205,5 & 363,5 \\
\hline \multicolumn{3}{|c|}{5 винтов } \\
\hline 2 & 648,0 & 581,7 \\
\hline 2,5 & 414,7 & 465,3 \\
\hline 3 & 288,0 & 387,8 \\
\hline 3,5 & 211,6 & 332,4 \\
\hline 4 & 162,0 & 290,8 \\
\hline \multicolumn{3}{|c|}{6 винтов } \\
\hline 2 & 540,0 & 484,7 \\
\hline 2,5 & 345,6 & 387,8 \\
\hline 3 & 240,0 & 323,1 \\
\hline 3,5 & 176,3 & 277,0 \\
\hline
\end{tabular}

Заключение. В работе рассмотрен вариант конструкция пилы дисковой сборной со съемными сегментами, позволяющая уменьшить время на замену инструмента.

Определено максимальное значение силы, приходящейся на крепежные элементы, достигаемой при вращении пилы на холостом ходу и равной силе инерции сегмента $F_{\text {и }}=10179 \mathrm{H}$, а также максимальная скорость подачи при полной загрузке привода, которая составила $V_{s}=$ $=14,08 \mathrm{~m} /$ мин.

По результатам расчета крепежных элементов на смятие и срез определено, что для крепления сегментов потребуются винты А2.M3-6gx3,5.109 (ГОСТ 17475) в количестве 6 шт.

Проведены исследования по определению зависимости напряжения среза $\tau_{\mathrm{cp}}$, МПа, и смятия $\sigma_{\text {см}}$, МПа от частоты вращения $n$, мин $^{-1}$, а также зависимости напряжения среза $\tau_{\mathrm{cp}}$, МПа, и смятия $\sigma_{\mathrm{cm}}$, МПа, от диаметра резьбы винта $d$, мм, и их количества. Максимально возможная допустимая частота вращения пилы составила $n=4664$ мин $^{-1}$, а наилучшим вариантом крепежных элементов будет 6 винтов A2.M3-6gx3,5.109 (ГОСТ 17475).

\section{Список литературы}

1. Глебов И. Т. Резание древесины. Екатеринбург: УГЛТУ, 2001. 151 с.

2. Дисковая пила: пат. 7982 Респ. Беларусь, МПК В 23 D 47/00, В 23 D 61/02, С 23 C 14/32/ И. В. Мурашова, В. А. Хлебцевич, И. Л. Поболь, Ю. В. Соколов, А. Э. Паршуто // Нац центр интеллектуал. собственности. 2020. С. 5.

3. Круглая пила для древесины с эффектом самозаточки: пат. 2690879 Рос. Федерация, МПК В 27 В 33/08, В 23 D 61/02 / В. П. Ивановский, А. Д. Платонов, А. М. Волганкин, Р. А. Недиков; заявитель Воронежский гос. лесотехн. ун-т имени Г. Ф. Морозова. № 2018145389; заявл. 19.12.2018; опубл. 06.06.2019 // Регистр интеллектуал. промышл. собственности. 2020. С. 6.

4. Дисковая пила: пат. 1544558 СССР, МПК В 27 В 33/08, В 23 D 61/02, В 23 D 61/04/ Т. А. Носовский, В. И. Белошицкий, И. М. Пишник, С. В. Зубик; заявитель Львовский лесотехн. ин-т № 4390994; заявл. 20.01.1988; опубл. 23.02.1990 // Нац центр интеллектуал. собственности. 1990. С. 2.

5. Строй-подсказка / Особенности пилы Геллера. M.,2015. URL: https://stroy-podskazka.ru (дата обращения: 28.11.2020).

6. Завойских Г. И., Протас Г. И., Лой В. Н. Первичная переработка древесного сырья на лесозаготовительных предприятиях: учеб.-метод. пособие. Минск: БГТУ, 2010. 133 с.

7. BBK-C / Многопильные станки. Минск, 2020. URL: https://vvks.by (дата обращения: 28.11.2020).

8. Детали из древесины и древесных материалов. Припуски на механическую обработку: ГОСТ 7307-2016. Введ. 01.10.2018. Минск: Гос. ком. по стандартизации Респ. Беларусь, 2018. 20 с. 
9. Гришкевич А. А. Механическая обработка древесины и древесных материалов, управление процессами резания: учеб.-метод. пособие. Минск: БГТУ, 2012. $111 \mathrm{c.}$

10. Бурносов Н. В., Гриневич С. А. Проектирование и производство деревообрабатывающего оборудования. Лабораторный практикум. Минск: БГТУ, 2008. 143 с.

11. Винты с потайной головкой точности А и В. Конструкция и размеры: ГОСТ 17475-80. Введ. 01.01.1982. Минск: Гос. ком. по стандартизации Респ. Беларусь, 2008. 10 с.

12. Детали машин / Расчет болтовых соединений. Уфа, 2020. URL: http://www.detalmach.ru (дата обращения: 28.11.2020).

\section{References}

1. Glebov I. T. Rezaniye drevesiny [Cutting wood]. Yekaterinburg, UGLTU Publ., 2001. 151 p.

2. Diskovaya pila [Circular saw]. Patent 7982 BY, no. u 20110634, 2012.

3. Kruglaya pila dlya drevesiny s effektom samozatochki [Round wood saw with self-sharpening effect]. Patent 2690879 RF, no. 2018145389, 2019.

4. Diskovaya pila [Disk saw]. Patent 1544558, No. 43990994, 1990.

5. Stroy-podskazka. Osobennosti pily Gellera [Stroy tip. Features of the Geller saw]. Moscow, 2015. Available at: https://stroy-podskazka.ru (accessed 28.11.2020).

6. Zavoyskikh G. I., Protas P. A., Loy V. N. Pervichnaya pererabotka drevesnogo syr'ya na lesozagotovitel'nykh predpriyatiyakh [Primary processing of wood raw materials at logging enterprises: studies]. Minsk, BGTU Publ., 2010. 133 p.

7. BBK-C Mnogopilnyye stanki [Multi-saw machines]. Minsk, 2020. Available at: https://vvks.by (accessed 28.11.2020).

8. GOST 7307-2016. Detali iz drevesiny $i$ drevesnykh materialov. Pripuski na mekhanicheskuyu obrabotku [Parts made of wood and wood materials. Allowances for mechanical processing]. Minsk, Gosudarstvennyy komitet po standartizactsii Resp. Belarus' Publ., 2018. 20 p. (In Russian).

9. Grishkevich A. A. Mekhanicheskaya obrabotka drevesiny i drevesnykh materialov, upravlenyie protsessami rezaniya [Mechanical processing of wood and wood materials, control of cutting processes]. Minsk, BGTU Publ., 2012. 111 p.

10. Burnosov N. V. Grinevich S. A. Proyektirovaniye i proizvodstvo derevoobrabatyvayushchego oborudovaniya [Design and production of woodworking equipment]. Minsk, BGTU Publ., 2008. 143 p.

11. GOST 17475-80. Vinty s potaynoy golovkoy tochnosti A $i$ V. Konstruktsiya i razmery [Countersunk head screws of precision A and B. Design and dimensions]. Minsk: Gosudarstvennyy komitet po standartizatsii Resp. Belarus' Publ., 2008. 10 p. (In Russian).

12. Detali mashin. Raschet boltovykh soyedineniy [Details of machines. Calculation of bolted connections]. Ufa, 2020. Available at: http://www.detalmach.ru (accessed 28.11.2020) (In Russian).

\section{Информация об авторах}

Гришкевич Александр Александрович - кандидат технических наук, доцент, заведующий кафедрой деревообрабатывающих станков и инструментов. Белорусский государственный технологический университет (220006, г. Минск, ул. Свердлова, 13a, Республика Беларусь). E-mail: dosy@belstu.by

Гриневич Сергей Анатольевич - кандидат технических наук, доцент, доцент кафедры деревообрабатывающих станков и инструментов. Белорусский государственный технологический университет (220006, г. Минск, ул. Свердлова, 13a, Республика Беларусь). E-mail: gres410a@ya.ru

Алифировец Григорий Васильевич - инженер кафедры деревообрабатывающих станков и инструментов. Белорусский государственный технологический университет $(220006$, г. Минск, ул. Свердлова, 13а, Республика Беларусь). E-mail: alifirovez@tut.by

\section{Information about the authors}

Grishkevich Aleksandr Aleksandrovich - PhD (Engineering), Associate Professor, Head of the Department of Woodworking Machines and Tools. Belarusian State Technological University (13a, Sverdlova str., 220006, Minsk, Republic of Belarus). E-mail: dosy@belstu.by

Grinevich Sergey Anatol'yevich - PhD (Engineering), Associate Professor, Assistant Professor, the Department of Woodworking Machines and Tools. Belarusian State Technological University (13a, Sverdlova str., 220006, Minsk, Republic of Belarus). E-mail: gres410a@ya.ru

Alifirovets Grigoriy Vasil'yevich - engineer, the Department of Woodworking Machines and Tools. Belarusian State Technological University (13a, Sverdlova str., 220006, Minsk, Republic of Belarus). E-mail: alifirovez@tut.by 